\title{
Retrograde Renal Cooling to Minimize Ischemia
}

\author{
Janet L. Colli, Philip Dorsey, Leah Grossman, Benjamin R. Lee \\ Tulane University School of Medicine, New Orleans, LA, USA
}

\section{ABSTRACT}

Objective: During partial nephrectomy, renal hypothermia has been shown to decrease ischemia induced renal damage which occurs from renal hilar clamping. In this study we investigate the infusion rate required to safely cool the entire renal unit in a porcine model using retrograde irrigation of iced saline via dual-lumen ureteral catheter.

Materials and Methods: Renal cortical, renal medullary, bowel and rectal temperatures during retrograde cooling in a laparoscopic porcine model were monitored in six renal units. Iced normal saline was infused at $300 \mathrm{cc} /$ hour, $600 \mathrm{cc} /$ hour, $1000 \mathrm{cc} /$ hour and gravity (800 cc/hour) for 600 seconds with and without hilar clamping.

Results: Retrograde cooling with hilar clamping provided rapid medullary renal cooling and significant hypothermia of the medulla and cortex at infusion rates $\geq$ $600 \mathrm{cc} /$ hour. With hilar clamping, cortical temperatures decreased at $-0.9^{\circ} \mathrm{C} / \mathrm{min}$. reaching a threshold temperature of $26.9^{\circ} \mathrm{C}$, and medullary temperatures decreased at $-0.90 \mathrm{C} / \mathrm{min}$. reaching a temperature of $26.1^{\circ} \mathrm{C}$ over 600 seconds on average for combined data at infusion rates $\geq 600 \mathrm{cc} /$ hour. The lowest renal temperatures were achieved with gravity infusion. Without renal hilum clamping, retrograde cooling was minimal at all infusion rates.

Conclusions: Significant renal cooling by gravity infusion of iced cold saline via a duel lumen catheter with a clamped renal hilum was achieved in a porcine model. Continuous retrograde irrigation with iced saline via a two way ureteral catheter may be an effective method to induce renal hypothermia in patients undergoing robotic assisted and/or laparoscopic partial nephrectomy.

\section{ARTICLE INFO}

\section{Key words:}

Models, Animal; Kidney;

Nephrectomy; Robotics;

Surgical Procedures,

Operative; Laparoscopy

Int Braz J Urol. 2013; 39: 37-45

Submitted for publication:

August 17, 2012

Accepted after revision:

January 10, 2013

\section{INTRODUCTION}

For the treatment of small renal masses, nephron sparing surgery has been shown to provide long-term benefits compared to radical nephrectomy (1). Subsequently, partial nephrectomy has become the treatment of choice for patients with small, organ confined renal tumors $(2,3)$. Compared to open nephron-sparing surgery, laparoscopic and robotic assisted partial nephrectomy provides the additional benefits of decreased pain medication requirements, shorter hospital stay, more rapid return to full activity and improved cosmetic results (4) in addition to offering equal cancer control (5).
During partial nephrectomy, renal hypothermia has been shown to decrease ischemia induced renal damage and minimize reperfusion injury, which occurs from renal hilar clamping (68). The benefits of renal hypothermia were first described by Ward et al., who found the optimal temperature for reno-protective effect during temporary ischemia is between $15-20^{\circ} \mathrm{C}$ (9). Subsequent researchers have evaluated the cellular mechanisms by which renal hypothermia protects against serious long term renal damage (10). While cold ischemia is easily applied during open nephron sparing surgery, it is technically difficult to implement in laparoscopic and robotic approaches 
due to difficulty in introducing and maintaining ice slurry via trocars (11).

Several authors have described alternative methods of inducing renal hypothermia during laparoscopic partial nephrectomy with resultant decreases in warm ischemia related kidney injury (12-17). Retrograde ureteric renal perfusion cooling was one of the first alternative cooling methods described in 2002 by Landman et al. (18). Using a ureteral access sheath, ice cold saline was infused to cool the kidney from the collecting system outward to the cortex (18). Further attempts to refine the technique utilized a different ureteral catheters (19). While previous studies have demonstrated the feasibility of retrograde renal hypothermia, potential complications and limited data concerning technical considerations have limited its application clinically (20).

We recently reported a head-to-head comparison of ice slurry surface cooling and retrograde perfusion cooling employing a dual lumen ureteral catheter to investigate the effects on the renal cortex, medulla, and surrounding viscera (21). We found both methods were able to equally and effectively cool the kidney in an off-clamp animal model (21). In the current study, we compare and identify the optimal infusion rate required to safely cool the entire renal unit, in a porcine model using retrograde irrigation of iced saline via dual-lumen ureteral catheter. In addition, we assess regional cooling temperatures, and compare the ability of retrograde cooling with hilar clamping to an unclamped renal model.

\section{MATERIALS AND METHODS}

After approval from the Institutional Animal Use Committee, we performed a study monitoring renal temperatures during retrograde cooling in a laparoscopic porcine model. A rectal temperature probe and three digital percutaneous temperature probes were used to monitor core body and renal temperatures in 6 renal units.

In the lateral decubitus position, pneumoperitoneum using a Veress needle was achieved with subsequent placement of a $12 \mathrm{~mm}$ camera port. Two subsequent ports were placed, and the kidney was dissected free from Gerota's fascia.
The renal collecting system was cannulated with a 12/14 Fr dual lumen ureteral catheter (Cook Medical, Inc., Bloomington, IN). This was accomplished by transecting the distal ureter and subsequently performing an open ureterostomy. We intubated the ureter with a 12/14 FR dual lumen catheter and advanced it to the renal pelvis (Figure-1). Attempts at cannulating the ureter laparoscopically were unsuccessful. A digital temperature probe (Dostmann Electronic KG., Mannheim, Germany) was inserted percutaneously into the cortical tissue of the kidney at a depth of $1 \mathrm{~cm}$, and another was inserted into the medulla at a depth of $2.5 \mathrm{~cm}$ (Figure-2). A third probe was placed in the most dependant portion of bowel loops to capture serosal temperature changes. A continuous rectal probe was used to monitor the animal's core body temperature. Iced normal saline (temperature range $1.0^{\circ} \mathrm{C}-1.3^{\circ} \mathrm{C}$ ) was then infused via different rates (gravity at a height of $150 \mathrm{~cm}$ above the kidney, $300 \mathrm{cc} /$ hour, $600 \mathrm{cc} /$ hour, $1,000 \mathrm{cc} /$ hour) through the distal port of the double lumen catheter and allowed to drain via passive run-off from the proximal port. Our gravity infusion rate was calculated to be approximately 800cc/second.

Renal cortical, renal medullary, bowel and rectal temperatures were monitored continuously and values were recorded during each of the different infusion rates, in 30 second intervals, (n $=20$ ) for 600 seconds. Trials were repeated in 6 renal units and temperatures for the 6 renal units were combined to one data set. In addition, half of the 6 renal units were exposed to retrograde cooling with renal hilar clamping and the other half were exposed to retrograde cooling without hilar clamping. All trials were separated by a warming phase, returning (core, renal, bowel) temperatures to baseline. The collecting system was not entered in any of the trials.

Renal cortical and medullary temperature data points were obtained with each rate of retrograde infusion (with and without hilar clamping). Statistical analysis was performed to identify which of the infusion rates achieved optimal renal cooling. In addition, the maximal rate at which renal hypothermia was achieved during retrograde cooling with hilar clamping was compared to cooling temperatures achieved without 
Figure 1 - Set-up for laparoscopic ports and dual lumen ureteral catheter in the porcine model.

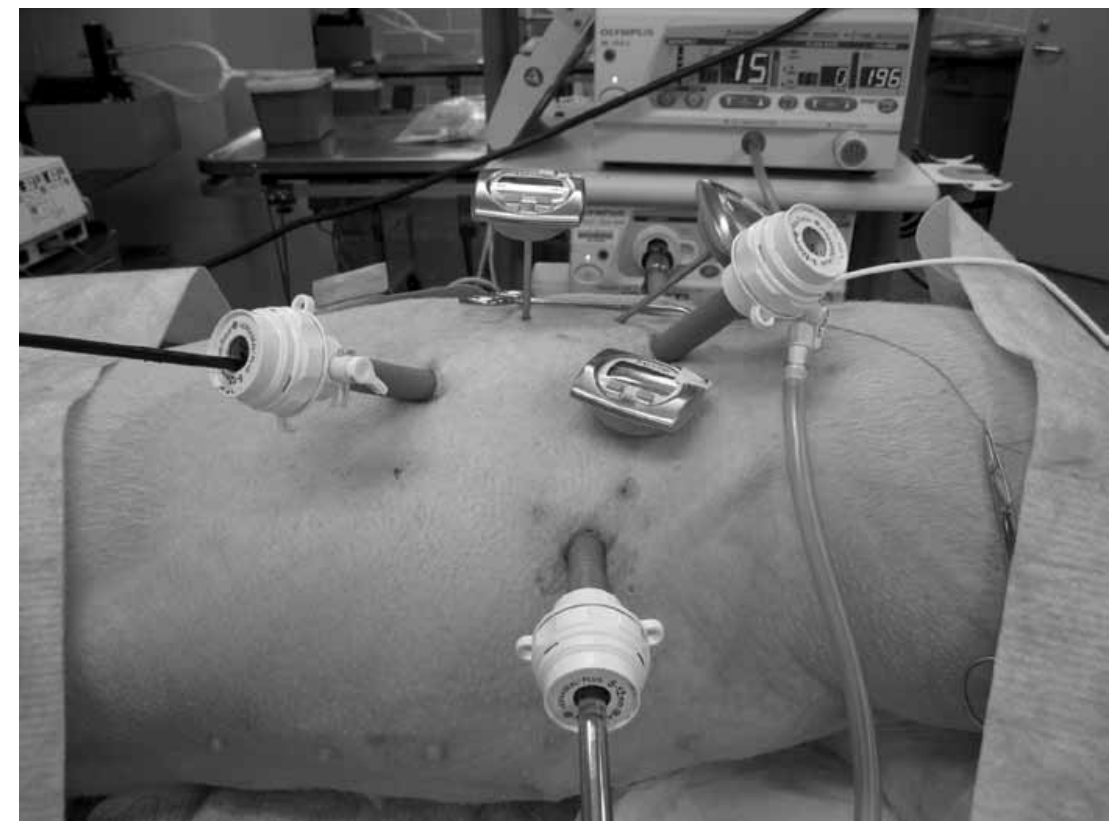

Figure 2 - Temperature probes in the cortical and medullary tissue of the kidney.

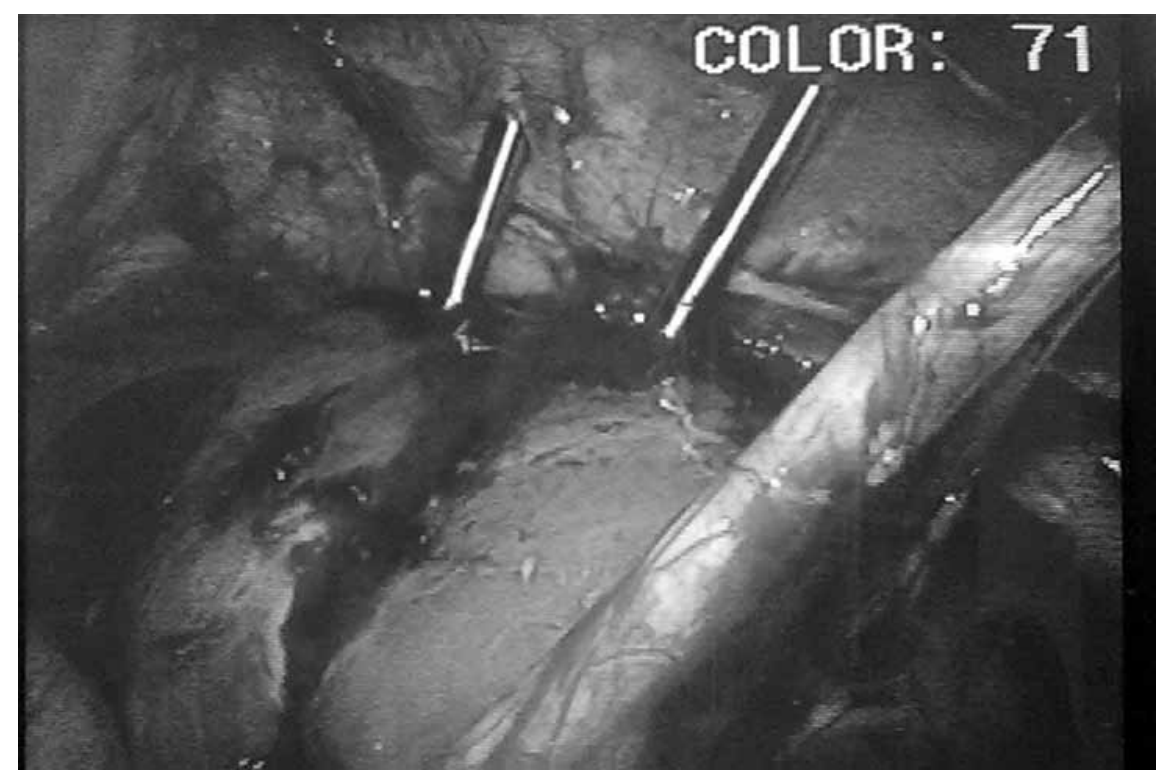


clamping. Statistical analysis was performed using SPSS statistical software for windows version 16.0 (Chicago: SPSS Inc).

\section{RESULTS}

To review outcomes of renal cortical and medullary temperatures without hilar clamping, we compiled the results into two groups, low infusion rates (less than $600 \mathrm{cc} /$ hour) and high infusion rates (equal to or greater than $600 \mathrm{cc} /$ hour). During ice cold saline infusion (while the renal hilum was not clamped), cortical temperature change for low infusion rates was $-0.006^{\circ} \mathrm{C} /$ min., reaching $35.1^{\circ} \mathrm{C}$, within 600 seconds, while medullary temperatures displayed $-0.09^{\circ} \mathrm{C} / \mathrm{min}$. over the same rates, reaching a threshold temperature of $34.9^{\circ} \mathrm{C}$. When the infusion rates were high, cortical temperatures decreased $-0.02^{\circ} \mathrm{C} /$ min., reaching $34.3^{\circ} \mathrm{C}$ within 600 seconds, and medullary temperature change was $-0.02^{\circ} \mathrm{C} / \mathrm{min}$. and reached $34.5^{\circ} \mathrm{C}$ in 600 seconds. Overall, du- ring ice cold saline infusion without renal hilum clamping, retrograde cooling was minimal at both high and low infusion rates.

Retrograde cooling with hilar clamping provided rapid medullary renal cooling and significant hypothermia of the medulla and cortex at high infusion rates. Cortical temperatures decreased at $-0.9^{\circ} \mathrm{C} / \mathrm{min}$. reaching a threshold temperature of $26.9^{\circ} \mathrm{C}$, and medullary temperatures decreased at $-0.9^{\circ} \mathrm{C} / \mathrm{min}$. reaching a temperature of $26.1^{\circ} \mathrm{C}$ over 600 seconds on average for combined data at high infusion rates with hilar clamping. Table-1 for summary of results of retrograde cooling at low and high infusion rates with hilar clamping.

Hilar clamping provided more rapid and more effective cooling than non-hilar clamping.

Figures 3a-c: graphs of infusion time versus temperature at infusion rates of: $600 \mathrm{cc} /$ hour, $1,000 \mathrm{cc} /$ hour, and gravity (infusion $=800 \mathrm{cc}$ ) hour) with the renal helium clamped. Results with the renal hilum unclamped, and at infusion

Table 1 - Retrograde cooling for low and high infusion rates with hilar clamping.

\begin{tabular}{lcccccc}
\hline & \multicolumn{3}{c}{ Infusion rates $<600 \mathrm{cc} /$ hour } & \multicolumn{2}{c}{ Infusion rates $\geq 600 \mathrm{cc} / \mathrm{hour}$} \\
& Rectum & Medulla & Cortex & Rectum & Medulla & Cortex \\
& 35.3 & 34.6 & 34.4 & 36.0 & 35.4 & 35.7 \\
Starting Temp $\left({ }^{\circ} \mathrm{C}\right)$ & 35.2 & 34.5 & 34.4 & 35.4 & 26.1 & 26.9 \\
Final Temp $\left({ }^{\circ} \mathrm{C}\right)$ & -0.01 & -0.01 & -0.005 & -0.06 & -0.94 & -0.88 \\
Velocity to Final $\left({ }^{\circ} \mathrm{C} /\right.$ min.) & 600 & 600 & 600 & 600 & 600 & 600 \\
Time to Final Temp (seconds) & 35.2 & 34.5 & 34.3 & 35.4 & 26.1 & 26.9 \\
Coldest Temp $\left({ }^{\circ} \mathrm{C}\right)$ & -0.02 & -0.02 & -0.02 & -0.06 & -0.94 & -0.98 \\
Velocity to Coldest $\left({ }^{\circ} \mathrm{C} / \mathrm{min}.\right)$ & 405 & 465 & 360 & 600 & 600 & 555 \\
Time to Coldest Temp (sec.) & -0.1 & -0.1 & -0.05 & -0.6 & -9.4 & -8.8 \\
Total Temp Change $\left({ }^{\circ} \mathrm{C}\right)$ & 35.3 & 34.5 & 34.4 & 35.6 & 32.8 & 32.0 \\
Avg Temp 0 - 300sec $\left({ }^{\circ} \mathrm{C}\right)$ & 35.2 & 34.5 & 34.3 & 35.4 & 27.2 & 27.6 \\
Avg Temp 300 - 600sec $\left({ }^{\circ} \mathrm{C}\right)$ & & & & & \\
\hline
\end{tabular}


Figure $3 \mathrm{~A}$ - Temperature versus infusion time with hilar clamped (infusion rate $=600 \mathrm{cc} / \mathrm{hour}$ ).

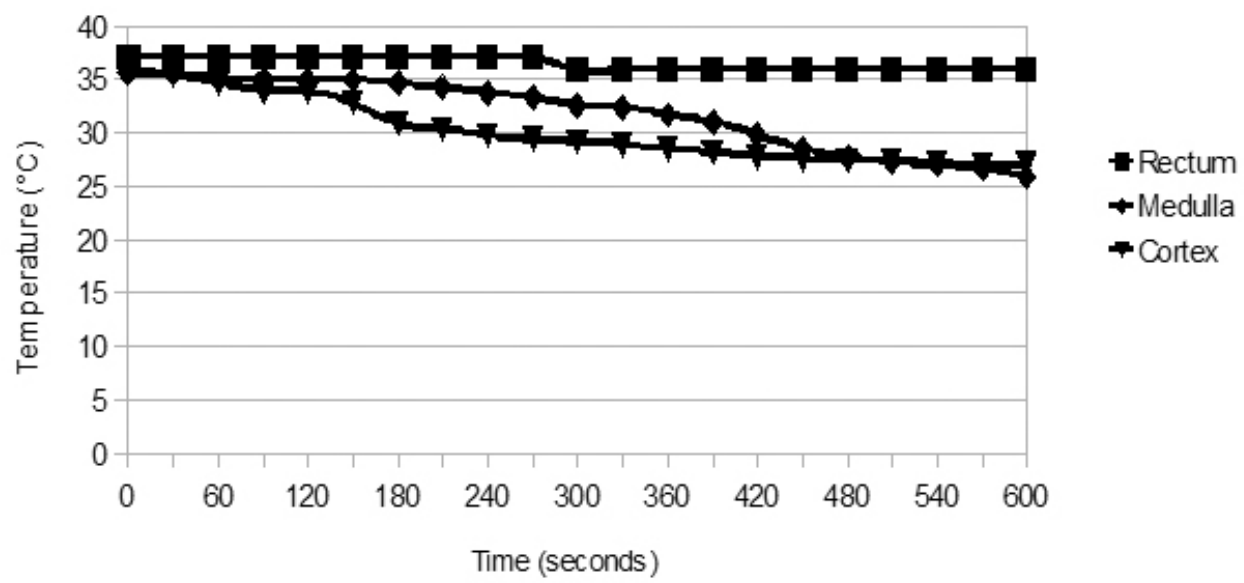

Figure 3B - Temperature versus infusion time with hilar clamped (infusion rate $=\mathbf{1 0 0 0} \mathrm{cc} / \mathrm{hour}$ ).

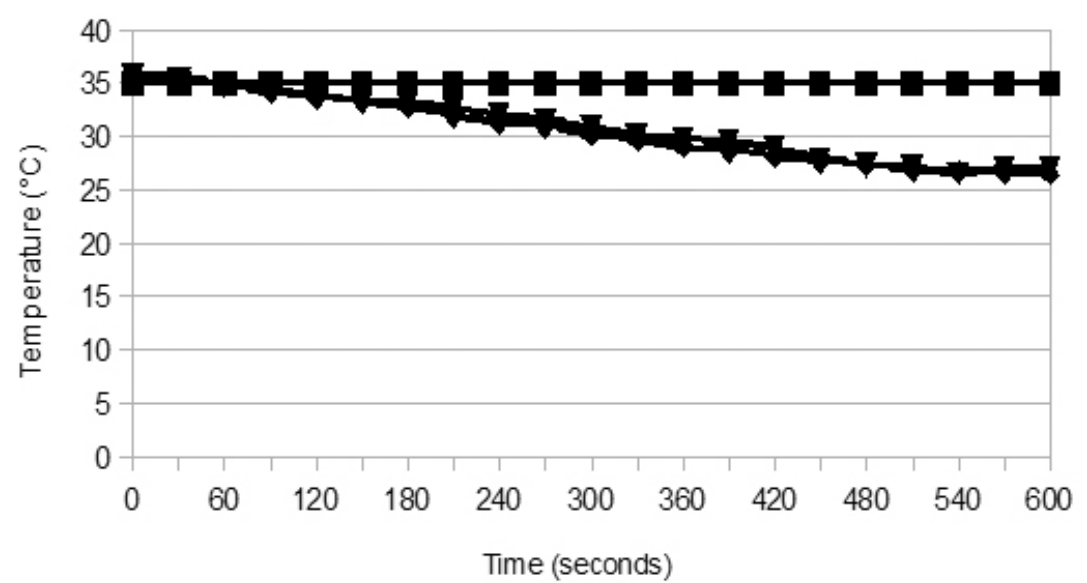

Figure 3C - Temperature versus infusion time with hilar clamped (infusion rate by gravity).

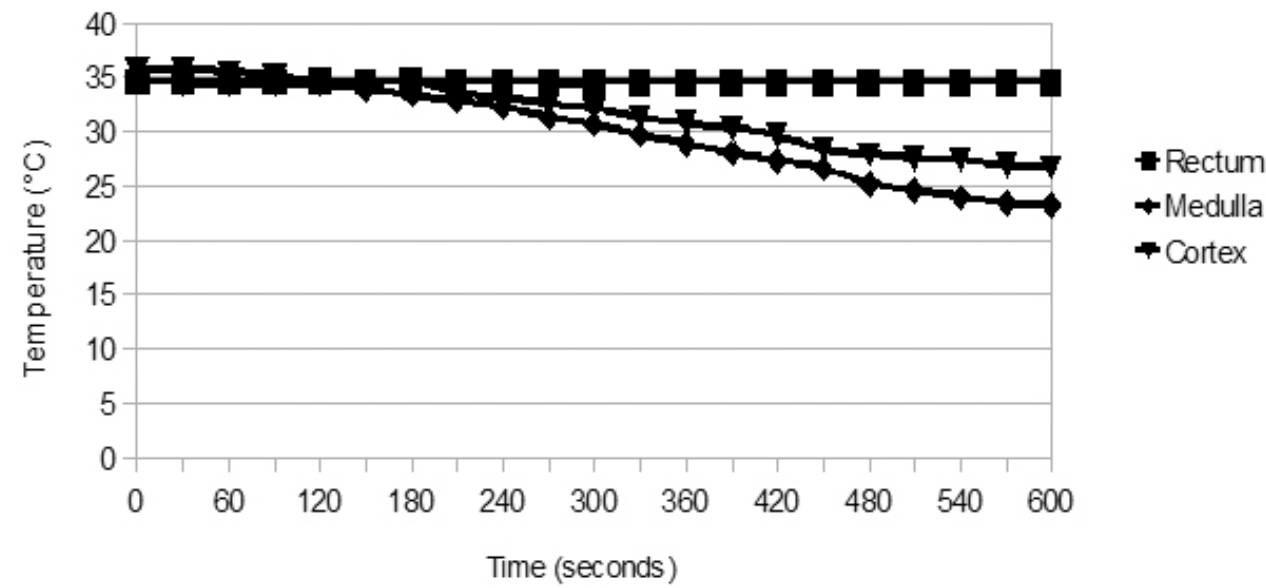


rates below $600 \mathrm{cc} /$ hour have not been displayed because changes in temperature were minimal. Gravity infusion provided the fastest decline and coldest renal temperatures, with cortical temperatures decreasing $-0.9^{\circ} \mathrm{C} / \mathrm{min}$. reaching a threshold temperature of $26.7^{\circ} \mathrm{C}$ over 600 seconds, and medullary temperatures decreasing $-1.13^{\circ} \mathrm{C} / \mathrm{min}$. reaching a temperature of $23.2^{\circ} \mathrm{C}$ over 600 seconds.

In summary, as the rate of iced saline infusion increased from 300 to $600 \mathrm{cc} /$ hour, cooling was more effective and the kidney was able to achieve reduced temperatures. Also hilar clamping provided more rapid and more effective cooling than non-hilar clamping. Retrograde cooling without hilar clamping demonstrated a pattern with significantly less cortical and medullary renal temperatures compared to retrograde cooling with hilar clamping. To review overall outcomes of renal cortical and medullary temperatures with and without hilar clamping, we compiled the results into two groups, temperatures reached within 300 seconds and temperatures reached after 300 seconds (Table 2).

Prior to cooling, baseline porcine kidneys temperature was $35.6^{\circ} \mathrm{C}$. The animal's average initial temperature was $35.6^{\circ} \mathrm{C}$, and the average final core body temperature was $35.0^{\circ} \mathrm{C}$. Bowel temperatures decreased more significantly in the surface cooling method. Starting at $35.0^{\circ} \mathrm{C}$, a $2.78^{\circ} \mathrm{C}$ decrease was noted after 10 minutes of surface cooling. Retrograde cooling demonstrated a $0.56^{\circ} \mathrm{C}$ decline in bowel serosa temperatures.

Table 2 - Retrograde cooling with and without hilar clamping for infusion rates greater than $600 \mathrm{cc} / \mathrm{hour}$.

\begin{tabular}{lcc}
\hline Without clamping of renal hilum & Medulla & Cortex \\
\hline Average Temp 0 - 300 seconds $\left({ }^{\circ} \mathrm{C}\right)$ & 34.9 & 34.7 \\
Average Temp $300-600$ seconds $\left({ }^{\circ} \mathrm{C}\right)$ & 34.9 & 34.7 \\
\hline With clamping of renal hilum & Medulla & Cortex \\
\hline Average Temp 0 - 300 seconds $\left({ }^{\circ} \mathrm{C}\right)$ & 33.6 & 32.9 \\
Average Temp $300-600$ seconds $\left({ }^{\circ} \mathrm{C}\right)$ & 30.8 & 30.6 \\
\hline
\end{tabular}

\section{DISCUSSION}

The renal cortex and medulla are vulnerable to ischemia related damages (10). Tissue ischemia causes the release of multiple inflammatory and vasoactive products causing further tissue damage. Continued hypoxia leads to cell death (10). Because renal metabolic activity is almost completely suspended at temperatures of $5^{\circ} \mathrm{C}$ to $20^{\circ} \mathrm{C}$, the goal of renal hypothermia is to reduce the temperature of the renal unit within this range to minimize ischemia related tissue injury (10). Previous studies suggest that if warm ischemia time is less than 20 minutes long term renal damage is minimal (11). However, recent publications suggest that every minute of warm ischemia can affect the risk of developing stage IV chronic kidney disease (11). Hence, the duration of warm ischemia without long-term renal damage continues to remain a subject of debate.

Previous authors have described various methods of renal cooling during laparoscopic partial nephrectomy, including intraoperative peri-renal ice slush (12) or cool saline irrigation (13-19), arterial infusion of cooled saline $(22,23)$. When employed, authors found a decreased in ischemic nephron damage following renal vessel clamping in animal and/or human subjects. Initial studies evaluating retrograde renal cooling during a partial nephrectomy were first described in 2002 by Landman et al. (18). Compared to our method of cold saline irrigation via a dual lumen ureteral catheter, Landman's technique included instilling the iced saline via an access sheath and draining the saline by a $7 \mathrm{Fr}$ pigtail catheter during open partial nephrectomies. He was able to achieving renal cortical temperatures of $24^{\circ} \mathrm{C}$ and medullary temperatures of $21^{\circ} \mathrm{C}$. Furthermore, histopathologic evaluation of the specimen revealed no associated damage to the collecting system urothelium from exposure to ice-cold saline irrigation (19). This initial study supported further investigation of retrograde cooling during laparoscopic procedures. Naya et al. (24) published a comparison of renal cooling techniques used during laparoscopic partial nephrectomy in a porcine model. Seven kidneys were cooled using ice slush alone, and seven were cooled using peri-renal circulation of 
cooled saline, and seven were cooled using irrigation of the collecting system with cooled saline after ice slush was placed around the kidney. They found that continuous irrigation of the collecting system with surrounding ice slush resulted in the lowest temperature at $60 \mathrm{~min}$. and the longest duration of cooling below $20^{\circ} \mathrm{C}$. (24). Furthermore, a study by Schuler (25) found regardless of whether arterial or arteriovenous clamping is performed, retrograde intrarenal cooling can reliably cool the porcine kidney to $28^{\circ} \mathrm{C}$, and renal $\mathrm{pO}_{2}$ is not significantly different between kidneys that undergo artery only versus en bloc hilar clamping (25). Of note, Formiga, et al. (26) found clamping artery only and arteriovenous intermittent clamping methods were less deleterious to the kidney and had superior overall outcomes compared to continuous arteriovenous clamping $(\mathrm{P}<0.001)$.

In 2003, Gill et al. (12) described a purely laparoscopic technique of renal hypothermia with ice slush. Gill was able to deliver ice slush in twelve partial nephrectomies, by introducing the ice through a laparoscopic bag to surround the kidney and essentially replicate standard open surgical practice (12). This method proved to be technically difficult and never became widely used in clinical practice. In 2007, Shikanov (27) performed a pilot study, assessing the feasibility of providing renal hypothermia in the porcine model by delivering microparticulate ice slurry during laparoscopy. This study showed efficient and rapid induction of renal hypothermia using microparticulate ice slurry delivered through $5 \mathrm{~mm}$ laparoscopic ports via laparoscopic suction/irrigators (25). Leeb et al. (2004) demonstrated a technique of arterial infusion of cooled saline during partial nephrectomy (22). However, placement of an intra arterial cooling catheter required additional operative and anesthesia time and never became widely used. In 2009, Madras et al. (23) developed a technique for angiographic delivery of the novel intra-arterial thermoplastic gel that allows temporary selective vascular occlusion with normal perfusion of the remaining kidney. This pilot study showed selective lower pole ischemia was able to be achieved in the porcine model (23). Further investigations are needed to evaluate the feasibility of ice slurries and gels on a large scale.
While these previously described methods of renal cooling have shown promise in improving outcomes, they have several limitations worth mentioning. First renal cooling with ice slush was reported to produce slightly prolonged operative times in porcine models. Also, peri-renal ice slush must be constantly replenished to achieve and maintain the desired effect. Significant volumes of ice slush within the abdomen may obscure the operative field and potentially cause a decrease in core temperature with associated adverse outcomes (24). In addition, it is difficult to contain the ice slush around the kidney in a controlled fashion and not have run off irrigation or slush to the bowel while performing laparoscopic surgery (20). Finally, studies have shown that exposure of the renal surface with ice slush for longer than 35 minutes is associated with worsening post operative renal function (14-17). Also placement of a ureteral access sheath has it's own unique risk of potential ureteral perforation when passing the access sheath (19). The technique of intra-arterial infusion of cold saline through the renal vasculature carries the risk of fluid overload due to excessive intravascular fluid (22). Furthermore, placement of the intra-arterial cooling catheter required additional operative and anesthesia time and increased operative cost (23).

The goals of our study were to evaluate retrograde cooling as a method to induce renal hypothermia in an ex-vivo setting. The results of our ex-vivo study suggest that circulation of ice-cold saline via a duel lumen catheter is feasible and effective in lowering renal cortical temperature within a range known to have a renal protective effect in a porcine model. Our study differs from previous attempts at retrograde cooling in that a ureteral access sheath is not employed, minimizing risk of ureteral dilation in a solitary kidney as well as potential ureteral perforation in passing the access sheath. This study also evaluated the safest and most effective means to administer retrograde cooling. We tested different rates of retrograde ice cold saline infusion, both with and without hilar clamping. We found rapid gravity infusion, with hilar clamping resulted in the coolest and most rapid method to achieve effective retrograde cooling. 
This study has several limitations that warrant mentioning. First, our study is limited by the small number of subjects. As a result, our findings may over or understate the actual impact of retrograde cooling on post-operative renal function. Furthermore, we did not demonstrate hypothermic renal temperatures could be maintained, by retrograde cooling, after violation of the collecting system (as may occur during a partial nephrectomy). In addition, with retrograde cooling, we were only able to achieve renal (medullary) temperatures of $23.2^{\circ} \mathrm{C}$ and not able to consistently achieve temperatures less than $20^{\circ} \mathrm{C}$. The ultimate impact of not achieving prolonged cold ischemia temperatures less than $20^{\circ} \mathrm{C}$ is unknown. Finally, our analysis would benefit from a case control design, with direct comparison to similar subjects undergoing partial nephrectomy without retrograde cooling. Future studies should also include evaluation of long-term measures of renal function after retrograde cooling, including serum creatinine and nuclear medicine renal scans.

\section{CONCLUSIONS}

The goal of our study was to investigate whether retrograde circulation of cold saline is an effective means of renal cooling that may be utilized during laparoscopic or robotic partial nephrectomy with hilum clamping. Renal hypothermia provides a nephro-protective effect which could preserve nephron tissue during ischemia and potentially improve post-operative morbidity in patients with significantly impaired preoperative renal function. We found the optimal method to achieve renal hypothermia is by gravity infusion of iced cold saline via a duel lumen catheter, with a clamped renal hilum. We propose that continuous retrograde irrigation of the collecting system with iced saline via a two way ureteral catheter is a simple, safe and effective method to induce renal hypothermia in a low pressure system which may be particularly beneficial for patients undergoing robotic assisted and/or laparoscopic partial nephrectomy with hilum clamping. Additional studies on the benefits and techniques of achieving renal hypothermia during laparoscopic and robot-assisted surgery in humans are warranted.

\section{CONFLICT OF INTEREST}

\author{
None declared.
}

\section{REFERENCES}

1. Clark MA, Shikanov S, Raman JD, Smith B, Kaag M, Russo $P$, et al.: Chronic kidney disease before and after partial nephrectomy. J Urol. 2011; 185: 43-8.

2. Campbell SC, Novick AC, Belldegrun A, Blute ML, Chow GK, Derweesh $\mathrm{IH}$, et al.: Guideline for management of the clinical T1 renal mass. J Urol. 2009; 182: 1271-9.

3. Joniau S, Vander Eeckt K, Van Poppel H: The indications for partial nephrectomy in the treatment of renal cell carcinoma. Nat Clin Pract Urol. 2006; 3: 198-205.

4. Gill IS, Kavoussi LR, Lane BR, Blute ML, Babineau D, Colombo JR Jr, et al.: Comparison of 1,800 laparoscopic and open partial nephrectomies for single renal tumors. J Urol. 2007; 178: 41-6.

5. Lane BR, Gill IS: 7-year oncological outcomes after laparoscopic and open partial nephrectomy. J Urol. 2010; 183: 473-9.

6. Thompson RH, Lane BR, Lohse CM, Leibovich BC, Fergany A, Frank I, et al.: Every minute counts when the renal hilum is clamped during partial nephrectomy. Eur Urol. 2010; 58: 340-5.

7. Thompson RH, Frank I, Lohse CM, Saad IR, Fergany A, Zincke $\mathrm{H}$, et al.: The impact of ischemia time during open nephron sparing surgery on solitary kidneys: a multi-institutional study. J Urol. 2007; 177: 471-6.

8. Thompson RH, Lane BR, Lohse CM, Leibovich BC, Fergany A, Frank I, et al.: Comparison of warm ischemia versus no ischemia during partial nephrectomy on a solitary kidney. Eur Urol. 2010; 58: 331-6.

9. Ward JP: Determination of the Optimum temperature for regional renal hypothermia during temporary renal ischaemia. Br J Urol. 1975; 47: 17-24.

10. Derweesh IH, Novick AC: Mechanisms of renal ischaemic injury and their clinical impact. BJU Int. 2005; 95: 948-50.

11. Porpiglia F, Renard J, Billia M, Musso F, Volpe A, Burruni R, et al.: Is renal warm ischemia over 30 minutes during laparoscopic partial nephrectomy possible? One-year results of a prospective study. Eur Urol. 2007; 52: 1170-8.

12. Gill IS, Abreu SC, Desai MM, Steinberg AP, Ramani AP, Ng C, et al.: Laparoscopic ice slush renal hypothermia for partial nephrectomy: the initial experience. J Urol. 2003; 170: 52-6.

13. Ames CD, Venkatesh R, Weld KJ, Morrissey K, Foyil KV, Shen $\mathrm{T}$, et al.: Laparoscopic renal parenchymal hypothermia with novel ice-slush deployment mechanism. Urology. 2005; 66: 33-7. 
14. Laven BA, Kasza KE, Rapp DE, Orvieto MA, Lyon MB, Oras $\mathrm{JJ}$, et al.: A pilot study of ice-slurry application for inducing laparoscopic renal hypothermia. BJU Int. 2007; 99: 166-70.

15. Kijvikai K, Viprakasit DP, Milhoua P, Clark PE, Herrell SD: A simple, effective method to create laparoscopic renal protective hypothermia with cold saline surface irrigation: clinical application and assessment. J Urol. 2010; 184: 1861-6.

16. Schoeppler GM, Klippstein E, Hell J, Häcker A, Trojan L, Alken $P$, et al.: Prolonged cold ischemia time for laparoscopic partial nephrectomy with a new cooling material: FrekaGelice--a comparison of four cooling methods. J Endourol. 2010; 24: 1151-4.

17. Shikanov S, Wille M, Large M, Razmaria A, Lifshitz DA, Chang $A$, et al:: Microparticulate ice slurry for renal hypothermia: laparoscopic partial nephrectomy in a porcine model. Urology. 2010; 76: 1012-6.

18. Landman J, Rehman J, Sundaram CP, Bhayani S, Monga M, Pattaras JG, et al.: Renal hypothermia achieved by retrograde intracavitary saline perfusion. J Endourol. 2002; 16: 445-9.

19. Landman J, Venkatesh $R$, Lee $D$, Vanlangendonck $R$, Morissey K, Andriole GL, et al.: Renal hypothermia achieved by retrograde endoscopic cold saline perfusion: technique and initial clinical application. Urology. 2003; 61: 1023-5.

20. Weld KJ, Koziol S, Montiglio C, Sorenson P, Cespedes RD, Bishoff JT: Feasibility of laparoscopic renal cooling with near-freezing saline irrigation delivered with a standard irrigator aspirator. Urology. 2007; 69: 465-8.

21. Shubha, Colli, Grossman, Johnsen, Lee: Renal Hypothermia: Direct Comparison of Surface versus Retrograde Perfusion Cooling for Induction of Cold Ischemia, Abstract and Presentation at Annual Urologic Association Meeting, Washington, DC. 2011.
22. Janetschek G, Abdelmaksoud A, Bagheri F, Al-Zahrani H, Leeb K, Gschwendtner M: Laparoscopic partial nephrectomy in cold ischemia: renal artery perfusion. J Urol. 2004; 171: 68-71.

23. Moinzadeh A, Flacke S, Libertino JA, Merhige J, Vogel JM, Lyall $\mathrm{K}$, et al.: Temporary segmental renal artery occlusion using reverse phase polymer for bloodless robotic partial nephrectomy. J Urol. 2009; 182: 1582-7.

24. Naya Y, Kawauchi A, Yoneda K, Ushijima S, Naitoh Y, Soh $J$, et al.: A comparison of cooling methods for laparoscopic partial nephrectomy. Urology. 2008; 72: 687-9.

25. Schuler TD, Perks AE, Fazio LM, Blew BD, Mazer D, Hare G, et al.: Impact of arterial and arteriovenous renal clamping with and without intrarenal cooling on renal oxygenation and temperature in a porcine model. J Endourol. 2008; 22: 2367-72.

26. Formiga CC, Mitre Al, Castilho LN, Buchpiguel CA, Marques FL, Radin A, et al.: Comparison of clamping modalities in a rabbit model of normothermic renal ischemia. J Endourol. 2011; 25: 1787-91.

27. Shikanov S, Wille M, Large M, Razmaria A, Lifshitz DA, Chang $A$, et al:: Microparticulate ice slurry for renal hypothermia: laparoscopic partial nephrectomy in a porcine model. Urology. 2010; 76: 1012-6.

Correspondence address:

Dr. Janet L. Colli

Tulane University School of Medicine, Department of Urology

1430 Tulane Avenue, SL-42, Room 3522 New Orleans, LA 70112

Fax: + 001504 988-5059

E-mail: jcolli.tulane@gmail.com 